Communications in Physics, Vol. 25, No. 4 (2015), pp. 375-382

DOI:10.15625/0868-3166/25/4/7671

\title{
ASSESSMENT OF RADIOACTIVE GASEOUS EFFLUENT RELEASED FROM NINH THUAN 1 NUCLEAR POWER PLANT UNDER SCENARIO OF INES-LEVEL 7 NUCLEAR ACCIDENT
}

\author{
NGUYEN TUAN KHAI AND LE DINH CUONG \\ Institute for Nuclear Science and Technology (INST), 179 Hoang Quoc Viet, Hanoi \\ E-mail: ntkhai@iop.vast.ac.vn \\ Received 06 December 2015 \\ Accepted for publication 31 December 2015
}

\begin{abstract}
Based on guidance RG 1.109, RG 1.111 published by United States Nuclear Regulatory Commission (US$N R C)$ our research concentrates on assessing radiation doses caused by radioactive substances released from the Ninh Thuan 1 nuclear power plant (NPP) to the environment under scenario of an INES-level 7 nuclear accident caused by two incidents: Station Black Out (SBO) and Loss of Coolant Accident (LOCA) using software RASCAL4.3 provided by the Emergency Operations Center of USNRC. The Ninh Thuan 1 NPP is assumed to use the VVER-1200 technology with a total power of $2400 \mathrm{MW}$ efrom two units. The input data for the model calculations is built based on the accident scenario, the technical parameters of VVER-1200 technology and the meteorology. In this work the meteorological data on dry and rainy seasons which are typical for the Ninh Thuan region was considered.

The maximum dose distributions were calculated within $40 \mathrm{~km}$ from the NPP site.The distributions are strongly affected by meteorological conditions. In the rainy season the dose values near the plant are higher than those in the dry season due to the deposition effect of the radioactive substances.

The calculation results show that consequences of the accident are very serious. A total radioactivity of radiological equivalence 225,000 TBq to ${ }^{131}$ I released to the atmosphere. Within $20 \mathrm{~km}$ the Total Effective Dose Equivalence (TEDE) values are very high, about several tens of times greater than the dose limit. It is requested to establish National Steering Board for Accident Response to direct the relevant authorities in response for the accident consequences and ensure for security in the area of NPP. The public communication, emergency preparedness plan, people evacuation must be implemented under the guidance of Circular 25/2014/TT-BKHCN.
\end{abstract}

Keywords: loss of coolant accident (LOCA), station black out (SBO), source term, radioactive release, maximum dose value, Ninh Thuan 1 NPP, VVER-1200, International Nuclear Event Scale (INES), RASCAL4.3.

\section{INTRODUCTION}

Currently, Vietnam is actively preparing infrastructure for the first two nuclear power plants (NPP) projects in the Ninh Thuan province, where the VVER-1200 (AES-2006) technology has been proposed for the NinhThuan 1 project consisting of two units with a total power of 2400 $\mathrm{MW}_{e}$. When going into operation, the NPP will release radioactive nuclides to atmosphere. The radioactive effluent undergoing dispersion in air and deposition on the ground will cause impact to the environment and human, especially for release from a nuclear accident. Therefore, study on 
transport and dispersion of radioactive substances in the atmosphere, and assessment of radiation dose to the public are of essential requirement for an NPP project. In addition, the calculation results will provide the necessary data for the Environmental Impact Assessment (EIA) and support for regulatory organization in reviewing the Safety Analysis Report (SAR)

Radioactive releases from various nuclear facilities, in general, may contribute to radiation exposure through two main pathways: (1) External exposures by direct radiation from radioactive plumes or from radioactive nuclides deposited on the ground, and (2) Internal exposure due to inhalation and ingestion of radioactive substances. The magnitude of exposure is dependent on atmospheric dispersion and deposition processes [1].

In this work we concentrate on assessing maximum radiation doses as a result of radioactive release from a nuclear accident with severe consequences assumed to occur at the Ninh Thuan 1 NPP. The magnitude of the accident was evaluated at level 7 which is the highest one defined by the International Nuclear Event Scale (INES) [2]. The scenario of the accident was built based on two incidents: Station Black Out (SBO) and Loss of Coolant Accident (LOCA). The latter is induced by a large break in the Reactor Coolant System (RCS). The accident leads to severe consequences, starting from the damage of the reactor core to failure of containment, and eventually release of radioactive substances to the environment. The assessment of the accident has been performed using RASCAL4.3, a computation code developed by the Emergency Operations Center of USNRC [3,4]. Building input for the code calculations consists of describing the accident scenario, technical parameters characteristics of the VVER-1200 technology and meteorology. The obtained calculation results include the released source term, radioactivity and maximum values of organ doses for the meteorology of the dry and rainy seasons in the Ninh Thuan region within $80 \mathrm{~km}$ radius from the NPP site. The maps of the radioactivity and dose distributions were established.

\section{RASCAL4.3 AND BUILDING DATA INPUT}

For modeling a NPP accident the Source Term to Dose model in RASCAL4.3 is used to evaluate the projected radiation doses from the plume of the released radioactive substances to people downwind based on entering information about the plant conditions. The dose pathways consist of cloud shine from the plume, inhalation from the plume, and ground shine from the deposited radioactive nuclides.

Building the data input for the model calculations includes:

a. Meteorology: Meteorological data is needed to the model behavior of the radioactive plume in the atmosphere. The minimum required data includes wind speed and direction, atmospheric stability, precipitation, air temperature. The goal is to provide the best representation of the weather conditions for the model run in both time (up to 48 hours starting from the release) and space (up to a distance of 50 miles or $80 \mathrm{~km}$ from the plant site). The RASCAL4.3 requires the initial weather data to be entered within a 2 hour window before the start of the release.

In this work the assessment of the radioactive dispersion and consequence of the accident was carried out at two times of the year: on the days of $17^{\text {th }}$ January and $26^{\text {th }}$ September 2013 which are typical for the dry and rainy seasons in the Ninh Thuan region, where the observed meteorological data are described [5].

b. Description of the scenario of the accident: Due to the SBO incident at the Ninh Thuan 1 NPP the LOCA phenomenon occurred. In addition, it is assumed that there was a large break in the 
RCS. Both these incidents made the LOCA to be occurred more quickly and led the reactor core to be uncovered. For the evolution of the accident, it is assumed that: (i) the reactor was shut down at 0:00 on 17 January 2013; (ii) the core was covered within three hours after shutting down, i.e. from 0:00 to 03:00; (iii) after that it was uncovered for six hours, from 03:00 to 09:00; and (iv) it was recovered at 09:00. During six hours of the water uncovering the fuel rods was heated up and melted down due to the decay heat. This caused release of the fission products from the core to the containment via the break in the RCS and, consequently, makes it possible to increase quickly temperature and pressure in the containment.

It is assumed that the integrity of the containment was maintained within the first two hours, i.e. from 03:00 to 05:00. After that, as a result of the continuing rise of temperature and pressure, the containment has failed and caused the radioactive release to the atmosphere which is assumed $10 \%$ per day.

The data on the VVER-1200 technological characteristics and evolution of the accident needed to build the input for the RASCAL4.3 calculations are summarized in Table 1 [6].

Table 1. The VVER-1200 technical parameters assumed to use at Ninh Thuan 1 NPP

\begin{tabular}{|l|l|}
\hline Event Type & Nuclear Power Plant \\
\hline Location & Phuoc Dinh \\
\hline Name: & Ninh Thuan 1 \\
\hline City, country, state & Ninh Phuoc, Ninh Thuan, Vietnam \\
\hline Lat/Long/Elev: & $11.3963^{\circ} \mathrm{N}, 109.0037^{\circ} \mathrm{E}, 20 \mathrm{~m}$ \\
\hline VVER-1200 Reactor parameters & \\
\hline Reactor power & $3,200 \mathrm{MWt}$ \\
\hline Peak rod burn-up & $60,000 \mathrm{MWd} / \mathrm{MTU}$ \\
\hline Containment type & PWR Dry Ambient \\
\hline Containment volume & $2.50 \mathrm{E}+06 \mathrm{ft}^{3}$ \\
\hline Design pressure & $72.52 \mathrm{~b} / \mathrm{in}^{2}$ \\
\hline Design leak rate & $0.2 \% / \mathrm{day}$ \\
\hline Coolant mass & $2.9 \mathrm{E}+05 \mathrm{~kg}$ \\
\hline Assemblies in core & 163 \\
\hline Steam generator & $\mathrm{U}-$ type \\
\hline SG water mass & $52,220 \mathrm{~kg}$ \\
\hline Source term & \\
\hline Type & Time core is uncovered \\
\hline Shutdown & $2013 / 01 / 17$ at $0: 00$ \\
\hline Core uncovered & $2013 / 01 / 17$ at 3:00 \\
\hline Core recovered & $2013 / 01 / 17$ at 9:00 \\
\hline
\end{tabular}

\section{RESULTS AND DISCUSSION}

For scenario of the NPP accident the RASCAL4.3 calculations give two main results: (1) source term for radioactive nuclides released to the atmosphere, and (2) maximum dose distribution (rem, mSv) up to 50 miles $(80 \mathrm{~km})$. For the scenario described above for the Ninh Thuan 
1 NPP there may have up to 60 radioactive nuclides predicted in the released source term. They are used to consider the radioactive dispersion and assess the maximum dose distribution from the accident. However, in this work only the radioisotopes whose activity were detected in two accidents Chernobyl and Fukushima are used to evaluate the magnitude (level) of the accident. They are presented in Table 2.

In principle the magnitude of a nuclear accident is evaluated as follows: Firstly the activity $A_{i}$ of each released radionuclide has to be attributed to the radiological equivalent one of ${ }^{131} \mathrm{I}$ by multiplying with factor $F_{i}$, and then the total radioactivity released $\left(A_{\text {total }}\right)$ is summed from all the obtained equivalent ones. From the data shown in Table 2 the total equivalent radioactivity is calculated as [2]:

$$
A_{\text {total }}=\Sigma\left(A_{i} \times F_{i}\right)=60.8 \times 10^{5} \mathrm{Ci} \sim 225 \times 10^{15} \mathrm{~Bq}=225,000 \mathrm{TBq}
$$

This is the radiological equivalence to ${ }^{131}$ I released to the atmosphere. This value shows that the accident is graded at the INES level 7: Major Accident [2].

Table 2. The radioactive nuclides used to evaluate the magnitude of the accident described above for the Ninh Thuan 1 NPP

\begin{tabular}{|l|l|l|l|l|l|}
\hline \hline Nuclide & Activity, $A_{i}(\mathrm{Ci})$ & $\mathrm{F}_{i}$ & Nuclide & Activity, $A_{i}(\mathrm{Ci})$ & $\mathrm{F}_{i}$ \\
\hline \hline${ }^{140} \mathrm{Ba}$ & $1.6 \mathrm{E}+4$ & none & ${ }^{106} \mathrm{Ru}$ & $3.3 \mathrm{E}+2$ & 6 \\
\hline${ }^{144} \mathrm{Ce}$ & $5.5 \mathrm{E}+2$ & none & ${ }^{132} \mathrm{Te}$ & $3.0 \mathrm{E}+4$ & 0.03 \\
\hline${ }^{134} \mathrm{Cs}$ & $1.3 \mathrm{E}+4$ & 3 & ${ }^{133} \mathrm{Xe}$ & $4.2 \mathrm{E}+5$ & 0 \\
\hline${ }^{137} \mathrm{Cs}$ & $8.9 \mathrm{E}+3$ & 40 & ${ }^{89} \mathrm{Sr}$ & $8.1 \mathrm{E}+3$ & 20 \\
\hline${ }^{131} \mathrm{I}$ & $4.6 \mathrm{E}+4$ & 1.0 & ${ }^{90} \mathrm{Sr}$ & $1.3 \mathrm{E}+3$ & 20 \\
\hline${ }^{99} \mathrm{Mo}$ & $6.3 \mathrm{E}+2$ & 0.08 & ${ }^{241} \mathrm{Am}$ & $1.5 \mathrm{E}-4$ & 8000 \\
\hline
\end{tabular}
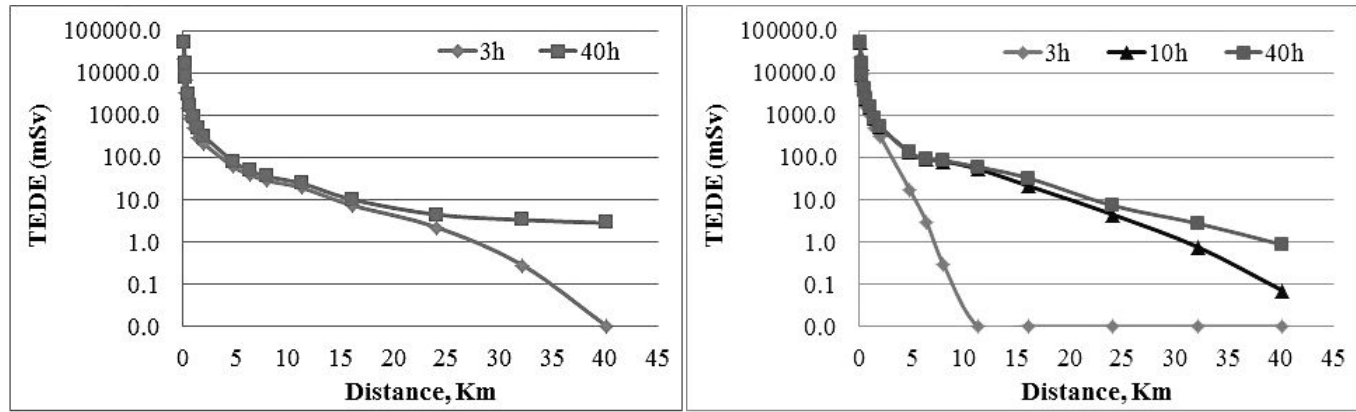

Fig. 1. The attenuation of the TEDE values (mSv) with respect to distance $(\mathrm{km})$ in the dry (left) and rainy (right) seasons

Based on the source term released the maximum value distribution for the TEDE dose for the dry season within a radius of 25 miles $(40.2 \mathrm{~km})$ around the plant was calculated at different 
dispersion times: 3, 10, 20, 30, 40 and 48 hours. The results are shown in Fig. 1, where we can see a proper attenuation of the dose with respect to the distance from the plant and after 10 hours the dose almost remains unchanged. So, for discussion, we used the calculation results obtained at the dispersion time of 20 hours as shown in Tables $3 \& 4$ for the dry and rainy seasons, respectively.

Table 3. Calculation results for maximum dose distribution (mSv) at 20 hours for the dry season up to 25 miles $(40.2 \mathrm{~km})$

\begin{tabular}{|l|l|c|c|c|c|c|c|c|}
\hline \multirow{2}{*}{ Distance from release } & Mile & 3 & 4 & 5 & 7 & 10 & 15 & 25 \\
\cline { 2 - 9 } & Km & 4.8 & 6.4 & 8 & 11.3 & 16.1 & 24.1 & 40.2 \\
\hline \multirow{3}{*}{ Dose $(\mathrm{mSv})$} & TEDE & 78 & 49 & 35 & 20 & 10 & 4.4 & 2.8 \\
\cline { 2 - 9 } & Thyroid CDE & 640 & 420 & 300 & 170 & 88 & 33 & 17 \\
\cline { 2 - 9 } & Inhalation CDE & 60 & 38 & 27 & 15 & 7.9 & 3.4 & 2.0 \\
\hline
\end{tabular}

Table 4. Calculation results for maximum dose distribution (mSv) at 20 hours for the rainy season up to 25 miles $(40.2 \mathrm{~km})$

\begin{tabular}{|l|l|c|c|c|c|c|c|c|}
\hline \multirow{2}{*}{ Distance from release } & Mile & 3 & 4 & 5 & 7 & 10 & 15 & 25 \\
\cline { 2 - 9 } & Km & 4.8 & 6.4 & 8 & 11.3 & 16.1 & 24.1 & 40.2 \\
\hline \multirow{3}{*}{ Dose $(\mathrm{mSv})$} & TEDE & 130 & 88 & 83 & 78 & 36 & 7.2 & 0.85 \\
\cline { 2 - 9 } & Thyroid CDE & 510 & 330 & 240 & 160 & 110 & 57 & 3.8 \\
\cline { 2 - 9 } & Inhalation CDE & 65 & 40 & 27 & 17 & 11 & 4.4 & 0.23 \\
\hline
\end{tabular}

The calculation results showed that:

- Within a radius of $4 \mathrm{~km}$ the doses are very high, even still about hundred times over the dose limit for publics. In general, the dose values decrease properly with respect to distance. In the rainy season TEDE's near the plant are higher than those in the dry season. This is due to strong deposition in dispersion of the radioactive substances in the rainy season.

- Up to $40 \mathrm{~km}$ the dose is still high for the dry season, approximately three times greater than the dose limit for publics. The annual limits for occupational and public exposures are 50 and $1 \mathrm{mSv}$ specified by USNRC and Regulatory Organization of Vietnam [7,8].

- Within $20 \mathrm{~km}$ the TEDE's are very high, about several tens of times over the dose limit, especially for the rainy season. This shows that the consequences of the accident are really serious. It is requested to establish National Steering Board for Accident Response to direct the relevant authorities, including National Emergency Response Organization, the People's Committee of Ninh Thuan province, military and police forces in response for the accident consequence and ensure for security in the plant area. The first priority is to evacuate people within the radius of $20 \mathrm{~km}$ around the plant. The consumption of food and milk in the region must be immediately stopped [9].

Fig. 2 shows the map of the TDED's distributions within $20 \mathrm{~km}$, where the affected areas with the TEDE values $\geqq 5 \mathrm{mSv}$ are about $44.4 \mathrm{~km}^{2}$ and $103 \mathrm{~km}^{2}$ for the dry and rainy seasons, respectively. It can be seen that in the dry season the radioactive dispersion is mostly in the South direction, concentrating in horizontal narrow area, but directed to the population zone. So the impact to public is serious, although the affected area is smaller than in the rainy one, where the dispersion is directed to the sea. 

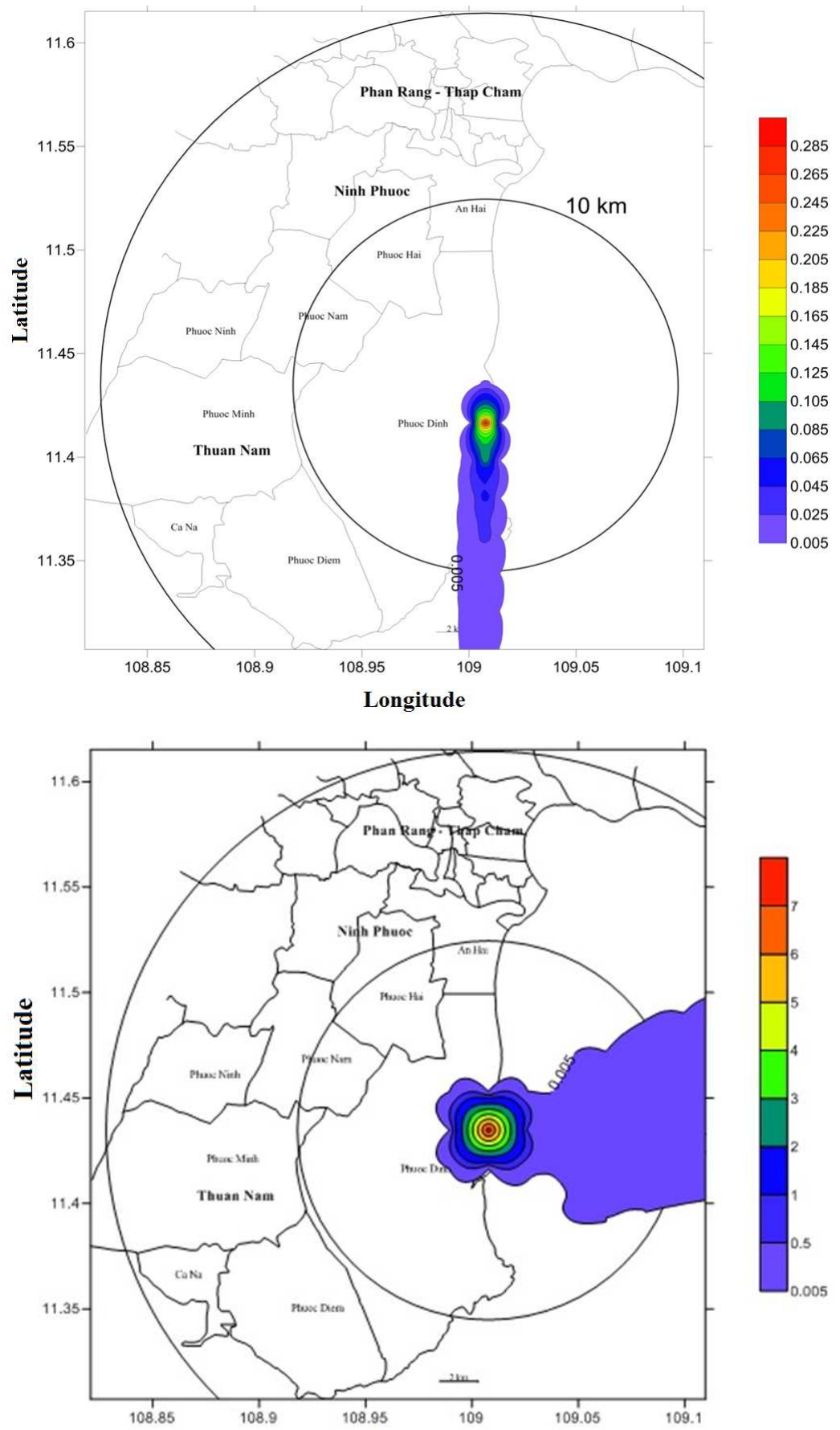

Fig. 2. Maps of TDED's distributions (Sv) within $20 \mathrm{~km}$ for the dry season (upper) and rainy season (lower) 


\section{CONCLUSION}

We proposed the scenario of a nuclear accident at the INES 7 level assumed to occur at the Ninh Thuan 1 NPP originated from two incidents: Station Black Out and Loss of Coolant Accident. The source term released and consequences of the accident have been assessed using the RASCAL4.3 code developed by the Emergency Operations Center of USNRC.

The data input for the code calculations was built based on the technical parameters of the VVER-1200 technology, the evolution of the accident and the meteorology within 48 hours covering the release. The maximum dose distributions were calculated up to 25 miles $(40.2 \mathrm{~km})$ from the plant site for the meteorological data on the dry and rainy seasons, which are typical for the annual weather in the Ninh Thuan region.

The calculation results showed that the dose distributions are affected by meteorological conditions. In the rainy season the TEDE values near the plant are higher than those in the dry season. This is due to strong deposition in the rainy season.

Within $20 \mathrm{~km}$ the TEDE values are still as high as several tens of times of the limit value for publics, especially for the rainy season. The affected areas with the TEDE values $\geqq 5 \mathrm{mSv}$ are about $44.4 \mathrm{~km}^{2}$ and $103 \mathrm{~km}^{2}$ for the dry and rainy seasons. Although the affected area is small, but the dispersion is directed to the population zone, the impact to public is serious if the accident is occurred in the dry season.

The public communication, plan for emergency preparedness and response, people evacuation must be implemented under the guidance of Circular 25/2014/TT-BKHCN [9].

\section{ACKNOWLEDGMENT}

This work has been performed in frame work of the National Program on Science and Technology in 2011-2015 Period under grant KC-05.04/11-15.

\section{REFERENCES}

[1] United States Nuclear Regulatory Commission and others, Regulatory Guide 1.109 Calculation of Annual Doses to Man from Routine Releases of Reactor Effluents for the Purpose of Evaluating Compliance with 10 CFR Part 50, Appendix I, Tech. report, 1977.

[2] I. INES, The International Nuclear and Radiological Event Scale User's Manual 2008 edition, 2008.

[3] Rascal42, 2012.

[4] J. Sagendorf, J. Goll, and W. Sandusky, XOQDOQ: Computer Program for the Meteorological Evaluation of Routine Effluent Releases at Nuclear Power Stations, Tech. report, Report No. NUREG/CR-2919, U.S. Nuclear Regulatory Commission; Washington, D.C; 1982.

[5] N. T. Khai, L. D. Cuong, D. X. Anh, D. D. Thang, T. V. Giap, N. T. T. Ha, V. T. Bac, and N. H. Quang, Communications in Physics 25 (2) (2015) 165.

[6] Status report 108-vver-1200 (v-491).

[7] JozefMisak, Subpart D-radiation Dose Limits for Individual Members of the Public; Part 20-standards for Protection Against Radiation, Tech. report, NRC Regulations (10 CFR).

[8] Circular No. 19/2012/TT-BKHCN issued on 08 Nov. 2012 by the Vietnam Ministry of Science and Technology (MOST) on Controlling and Ensuring the Radiation Safety for Professional and Public Exposure, Tech. report.

[9] Circular No. 25/2014/TT-BKHCN issued on 08 Oct. 2014 by the Vietnam Ministry of Science and Technology (MOST) on Preparing and Planning the Radiation Emergency Preparedness Safety for Professional and Public Exposure, Tech. report. 